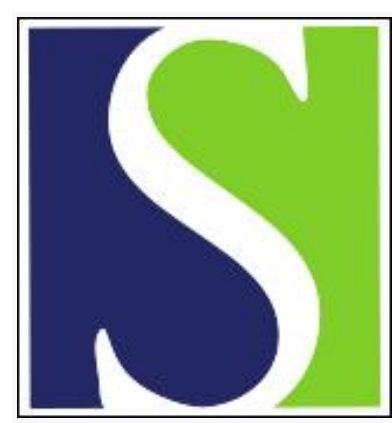

Scand J Work Environ Health 1985;11(4):287-293

https://doi.org/10.5271/sjweh.2220

Issue date: Aug 1985

Exposure to microorganisms, febrile and airway-obstructive symptoms, immune status and lung function of Swedish farmers.

by Malmberg P, Rask-Andersen A, Palmgren U, Hoglund S, Kolmodin-Hedman B, Stalenheim G

This article in PubMed: www.ncbi.nlm.nih.gov/pubmed/4059891

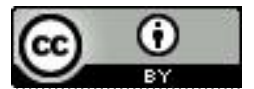




\title{
Exposure to microorganisms, febrile and airway-obstructive symptoms, immune status and lung function of Swedish farmers
}

\author{
by Per Malmberg, MD, ${ }^{1}$ Anna Rask-Andersen, $M D,{ }^{2}$ Urban Palmgren, $B A,{ }^{3}$ Sverker Höglund, MD, ${ }^{4}$ \\ Birgitta Kolmodin-Hedman, MD, ${ }^{5}$ Gunnemar Stålenheim, $M D^{6}$
}

\begin{abstract}
MALMBERG P, RASK-ANDERSEN A, PALMGREN U, HÖGLUND S, KOLMODIN-HEDMAN B, STÅLENHEIM G. Exposure to microorganisms, febrile and airway-obstructive symptoms, immune status and lung function of Swedish farmers. Scand $J$ Work Environ Health 11 (1985) 287-293. A questionnaire was sent to 512 farmers, members of a local farmer's health association. Eighty were interviewed, and their serum precipitins and total serum immunoglobulin $\mathrm{E}$ (IgE) values were determined. Forty-five underwent extensive pulmonary function tests. On the basis of the clinical evaluation it was estimated that $19 \%$ of the farmers had experienced febrile reactions (fever and/or shivering) following exposure to organic dust, $50 \%$ of the $19 \%$ having been exposed within the last 2.5 years. Common causes were moldy grain, hay, and woodchips. The pulmonary function, gas exchange, and chest radiographs of those who had previously had febrile reactions were normal. Only $13 \%$ showed positive precipitin reactions in Ouchterlony double-diffusion tests. With more sensitive tests, positive precipitins were found in $59 \%$, but they were negatively correlated with febrile episodes. Air samples collected during work with hay and grain on 21 farms contained between $10^{7}$ to $2 \times 10^{9}$ microorganisms $/ \mathrm{m}^{3}$. The highest values were associated with symptoms of alveolitis. Eleven percent of the farmers reported obstructive chest symptoms following exposure to organic dust. This group showed decreased pulmonary function and elevated serum IgE levels and included a high proportion of smokers and exsmokers. No correlation was found between febrile and obstructive reactions.
\end{abstract}

Key terms: extrinsic allergic alveolitis, farmer's lung, fungi XR allergens, grain, hypersensitivity pneumonitis, number of microorganisms in air samples, precipitins, pulmonary gas exchange, respiratory function tests.

Symptoms of allergic alveolitis are common in farmers following repeated exposure to moldy hay, and there is a high frequency of precipitating antibodies against thermophilic actinomycetes among farmers who have experienced febrile reactions to such exposure $(11,13,22)$.

Occasional heavy exposure to mold dust may result in an acute pneumonitis that is clinically similar to allergic alveolitis, even in subjects without precipitating antibodies against molds (8).

Mold dust generated during farm work contains spores from different molds and also bacteria and may vary in amount and composition depending upon the material and the humidity and temperature conditions $(16,25)$. Thus climatic and farming condi-

1 Research Department, National Board of Occupational Safety and Health, Stockholm, Sweden.

2 Department of Clinical Physiology, University Hospital, Uppsala, Sweden.

3 Department of Microbiology, Swedish University of Agricultural Sciences, Uppsala, Sweden.

4 Farmer's Safety and Health Association, Stockholm, Sweden.

$s$ Medical Division, National Board of Occupational Safety and Health, Umeå, Sweden.

6 Department of Lung Medicine, University Hospital, Uppsala, Sweden.

Reprint requests to: Dr P Malmberg, Research Department, FFL, National Board of Occupational Safety and Health, S-171 84 Solna, Sweden. tions may influence the prevalence of alveolitis. Differences in these respects between countries might provide important clues as to the pathogenesis of this disease.

This investigation was undertaken to examine the occurrence of symptoms and the immune status and lung function of Swedish farmers following exposure to microorganisms, and also to determine the nature of the exposure causing symptoms of disease.

\section{Materials and methods}

A questionnaire was mailed to all the 512 farmers in the county of Dalecarlia who at the time of the study were members of the Swedish Farmers' Safety and Health Association (about one-sixth of the farmers in the area). The questionnaire concerned febrile reactions experienced at work, symptoms of airway obstruction, dyspnea, cough, and smoking habits.

A stratified sample of farmers was asked to attend an oral interview at a local medical center. The interviews were conducted by trained physicians or nurses and concerned, especially, work-related febrile reactions and respiratory symptoms. On the same occasion blood samples were taken.

One blood sample was analyzed for the presence of precipitating antibodies against six antigens [listed in 
table 2 of the Results section under ID(a)] with the use of an immunodiffusion test $[\operatorname{ID}(\mathrm{a})]$ (1), also known as the double-diffusion-in-gel method of Ouchterlony. A second blood sample was analyzed for precipitating antibodies against a panel of 16 antigens (table 2) with both an immunoelectroosmophoretic (IEOP) method (26), also called counterimmunoelectrophoresis, and the immunodiffusion [ID(b)] method. The same antigen extracts were used in the IEOP and ID(b) tests, but the extracts differed from those used in the ID(a) tests. A third blood sample was taken for the determination of the total immunoglobulin (Ig) $\mathrm{E}$ concentration in serum by the Phadebas IgE/PRIST ${ }^{\circledR}$ (Pharmacia Diagnostics, Uppsala) method.

Forty-five of the 80 interviewed farmers also underwent chest radiography and tests of lung function and exercise capacity at the Departments of Lung Medicine and Clinical Physiology at the University Hospital in Uppsala.

A graded exercise test using an electrically braked bicycle ergometer was carried out to the point of exhaustion. Blood samples were taken through a plastic cannula in the radial artery for the determination of arterial blood gases at rest, in the supine and sitting positions, and during exercise. Expired air was collected, and the expiratory volume and the carbon dioxide and oxygen fractions were determined for the calculation of alveolar and total ventilation, the alveoloarterial difference in oxygen tension, and dead space ventilation. The diffusing capacity of the lung for carbon monoxide was measured with the Filley steady-state method (9) at a work load of $150 \mathrm{~W}$ for the men and $120 \mathrm{~W}$ for the women.

The total lung capacity, residual volume, and airway conductance were measured at a breathing rate of $0.5 \mathrm{~Hz}$ in a closed body plethysmograph. Forced expiratory flow and volumes were measured in a dry rolling seal spirometer (Cardio-Pulmonary Instruments, model 220) with adequate frequency response.

The details of the procedures have been described elsewhere $(10,18)$. The participants gave their informed consent to the examinations and the experimental protocol was approved by the Ethical Committee of the Medical Faculty of Uppsala University.

Selected farms were visited, and mold dust samples were collected from the breathing zone, with a Nuclepore $0.1 \mu \mathrm{m}$ filter in a Millipore filter holder (inner diameter $37 \mathrm{~mm}$ with a cover, leaving an opening with an inner diameter of $4 \mathrm{~mm}$ ). Air was sucked through the filter holder for $5 \mathrm{~min}$ at a rate of $1 \mathrm{l} / \mathrm{min}$, while the subject was handling hay or grain. The sampled material was extracted with a $0.1 \%$ peptone solution containing Tween 80 . One aliquot was stained with acridine orange (28) and filtered through a Nuclepore filter which was dyed with Sudan black. The microorganisms were counted in an epifluorescence microscope. Microorganisms larger and smaller than $1.5 \mu \mathrm{m}$ were counted separately. Other aliquots were used for culturing on different agar media for the characterization of viable organisms.

\section{Calculations}

All the values for spirometry and gas exchange were calculated as the percentage of predicted values, local reference values being used for the men $(10,18)$. For the women other reference values were used for the spirometry (3); reference values for the oxygen tension in arterial blood, the alveoloarterial difference in oxygen tension, and the total dead space : tidal volume ratio (Vd : $\mathrm{Vt}$ ) were the same as those used for the men except that the reference values for a work load of $150 \mathrm{~W}$ were compared with values obtained at $120 \mathrm{~W}$ for the women, with the assumption of a similar relative work load. The maximal work rate which could be sustained for $6 \mathrm{~min}$ was calculated and expressed as the percentage of the values predicted from local reference values (20). Population estimates were obtained by multiplying sample mean values by the number of subjects in the stratum from which the sample was drawn, adding these values, and dividing by the number of subjects in the total population. Student's t-test and the chi-square test were used for calculating statistical significance.

\section{Results}

Of the 512 mailed questionnaires, 439 were answered completely $(86 \%)$. Sixty-nine percent of the respondents were men aged 42.6 (SD 12.2, range 17-72) years. The women were slightly younger [40.8 (SD 10.1, range 17-72) years].

Fifteen percent of the men were current smokers [compared with $30 \%$ of the general population (23)], $28 \%$ were exsmokers, and $57 \%$ had never smoked ("nonsmokers"). The corresponding figures for the women were 13,12 , and $75 \%$.

The subjects were divided into three groups according to the answers to the questionnaire: 28 with answers suggesting febrile reactions to mold dust, 91 with unspecified reactions to dust, and 320 farmers with no such reactions (referents).

All 28 subjects with suspected febrile reactions were asked to attend the oral interview. Fifteen subjects from the group with unspecified symptoms and 30 subjects from the reference group were randomly selected for the interview. After the initial selection, 21 of the 29 remaining subjects, who had also responded in the affirmative to the questions in the questionnaire concerning the occurrence of symptoms of asthma, wheezing or hay fever, were invited to the interview. Eighty of 94 invited subjects attended the interviews $(85 \%)$.

On the basis of the aforementioned interviews and additional interviews conducted in connection with 
Table 1. Clinical and serological data for 80 farmers.

\begin{tabular}{|c|c|c|c|c|c|c|c|c|}
\hline \multirow[b]{2}{*}{ Number of subjects } & \multicolumn{2}{|c|}{$\begin{array}{c}\text { Febrile reaction } \\
\text { only }\end{array}$} & \multicolumn{2}{|c|}{$\begin{array}{c}\text { Obstructive reaction } \\
\text { only }\end{array}$} & \multicolumn{2}{|c|}{$\begin{array}{l}\text { Febrile and } \\
\text { obstructive reactions }\end{array}$} & \multicolumn{2}{|c|}{ No reaction } \\
\hline & & 27 & & 14 & & 5 & & 34 \\
\hline Mean age (years) & 46.1 & (SD 11.1) & 53.0 & $(\mathrm{SD} 9.8)^{\star}$ & 49.4 & (SD 9.0) & 45.2 & (SD 9.9) \\
\hline $\begin{array}{l}\text { Smokers }(\%) \\
\text { Exsmokers }(\%) \\
\text { Nonsmokers }(\%)\end{array}$ & & $\begin{array}{r}7 \\
30 \\
63\end{array}$ & & $\begin{array}{l}21 \\
57 \\
21\end{array}$ & & $\begin{array}{l}40 \\
20 \\
40\end{array}$ & & $\begin{array}{l}18 \\
18 \\
65\end{array}$ \\
\hline $\begin{array}{l}\text { Mean } \lg E(\mathrm{kU} / \mathrm{l})^{\mathrm{a}} \\
\text { Median } \lg E(\mathrm{kU} / \mathrm{l})^{\mathrm{b}}\end{array}$ & $\begin{array}{l}29.4 \\
11.0\end{array}$ & $\begin{array}{l}(\mathrm{SD} 46.5) \\
(7 \%)\end{array}$ & $\begin{array}{r}369 \\
41.8\end{array}$ & $\begin{array}{l}(\text { SD } 80.3)^{* * *} \\
(29 \%)\end{array}$ & $\begin{array}{l}60.1 \\
24.2\end{array}$ & $\begin{array}{l}(\mathrm{SD} 69.8)^{\star * *} \\
(20 \%)\end{array}$ & $\begin{array}{l}30.3 \\
14.6\end{array}$ & $\begin{array}{l}(\mathrm{SD} 53.2) \\
(6 \%)\end{array}$ \\
\hline $\begin{array}{l}\text { Precipitins }^{c} \\
\text { ID(a) } \\
\text { ID(b) } \\
\text { IEOP }\end{array}$ & & $\begin{array}{r}15 \\
8 \\
50\end{array}$ & & $\begin{array}{r}7 \\
21 \\
79\end{array}$ & & $\begin{array}{r}\overline{40} \\
100\end{array}$ & & $\begin{array}{r}9 \\
21 \\
74\end{array}$ \\
\hline
\end{tabular}

a Student's t-test computed after logarithmic transformation of the $\lg E$ values. ( $\lg E=$ immunoglobulin $E$ )

$b$ The percentage of farmers with IgE values greater than or equal to $100 \mathrm{kU} / \mathrm{l}$ is in parentheses.

c Percentage of farmers with at least one positive percipitin reaction against tested antigens [ID $(a)=$ immunodiffusion method, laboratory $A$, trace reactions included; $I D(b)=$ immunodiffusion methods, laboratory $B$, trace reactions not included; IEOP = immunoelectro-osmophoresis, laboratory B, trace reactions not included]

* $p<0.05,{ }^{\star \star \star}$ $p<0.001$, difference from the "no reaction" group.

the subsequent physiological investigations, an "interview diagnosis" regarding the presence or absence of symptoms following exposure to organic dust was made. The symptoms were "febrile reactions" (fever and/or shivering) and "obstructive reactions" (chest tightness and/or wheezing). The symptoms were also qualified with regard to intensity, duration, frequency, and the time relation to exposure. After adjustment for the sampling method, a population estimate for the different diagnoses was calculated.

The population estimate for febrile reactions was $19 \%$ (with a confidence interval of 9 to $28 \%$ ). About half of the reactions were severe, requiring bed rest. Fifty percent of the farmers with febrile reactions had had an attack within the last 2.5 years, and seven out of ten had had more than one attack.

The febrile reactions occurred during or after the handling of material which was considered by more than two-thirds of these farmers as being unusually moldy. The most common cause was exposure to moldy grain $(62 \%)$. Other common causes were moldy hay $(16 \%)$ and the threshing of grain $(16 \%)$.

There were no statistically significant differences between farmers who had experienced a febrile reaction and those who had not with regard to age, smoking habits, serum IgE levels or clinical symptoms of work-related airway obstruction $(13 \%$ in both groups) (table 1).

Four of the 80 interviewed subjects had asthma which had been diagnosed earlier, corresponding to a calculated prevalence of $1 \%$ in the examined population. An additional $10 \%$ (population estimate) had work-related obstructive symptoms. These subjects were somewhat older and had higher serum IgE levels; there was also a higher proportion of exsmokers in this group (table 1). The population estimate was $3 \%$ for chronic bronchitis, $18 \%$ for other dustrelated cough, and $13 \%$ for upper airway symptoms.

Of 80 sera tested with the ID(a) method, the sera of two subjects gave strong precipitin lines against
Table 2. Precipitating antibodies measured with different methods in sera from 80 selected farmers.

\begin{tabular}{lllr}
\hline & \multicolumn{3}{c}{ Percentage positive sera } \\
\cline { 2 - 4 } Antigen & ID(a) & ID(b) & IEOP \\
\hline Micropolyspora faeni & 4 & 6 & 41 \\
Thermoactinomyces vulgaris & 0 & 1 & 8 \\
Cladosporium herbarum & 0 & 3 & 24 \\
Alternaria tenuis & 3 & 0 & 1 \\
Penicillium expansum & 1 & 1 & 10 \\
Aspergillus fumigatus & 4 & 4 & 37 \\
Aspergillus niger & & 0 & 11 \\
Aspergillus nidulans & & 0 & 1 \\
Aspergillus terreus & & 1 & 8 \\
Aspergillus flavus & & 1 & 11 \\
Mucor racemosus & & 0 & 1 \\
Aureobasidium pullulans & & 0 & 1 \\
Phoma betae & & 0 & 1 \\
Trichoderma viride & & 0 & 3 \\
Fusarium moniliforme & & 0 & 20 \\
Helminthosporium sativum & & 0 & 9 \\
\hline
\end{tabular}

a $I D(a)=$ immunodiffusion method, laboratory $A$, trace reactions included; $I D(b)=$ immunodiffusion method, laboratory $\mathrm{B}$, trace reactions not included; IEOP $=$ immunoelectro-osmophoresis, laboratory $\mathrm{B}$, trace reactions not included.

Aspergillus fumigatus, and the serum of one subject was positive against Alternaria. In addition, weak precipitates against Micropolyspora faeni, Aspergillus fumigatus, Penicillium, and Alternaria were found.

Precipitation arcs were observed against one or more of 16 antigens in $68 \%$ of the sera tested with the IEOP method and in $18 \%$ of those tested with the ID(b) technique (weak precipitin lines not included). The most common precipitins were directed against $M$ faeni (table 2). No positive correlation between the presence of precipitating antibodies and febrile reactions was found with either of the three methods (table 1), even when the time of the last febrile reaction was taken into account (figure 1), when individual antigens were tested, or when the sum of precipitates in each individual was considered. 


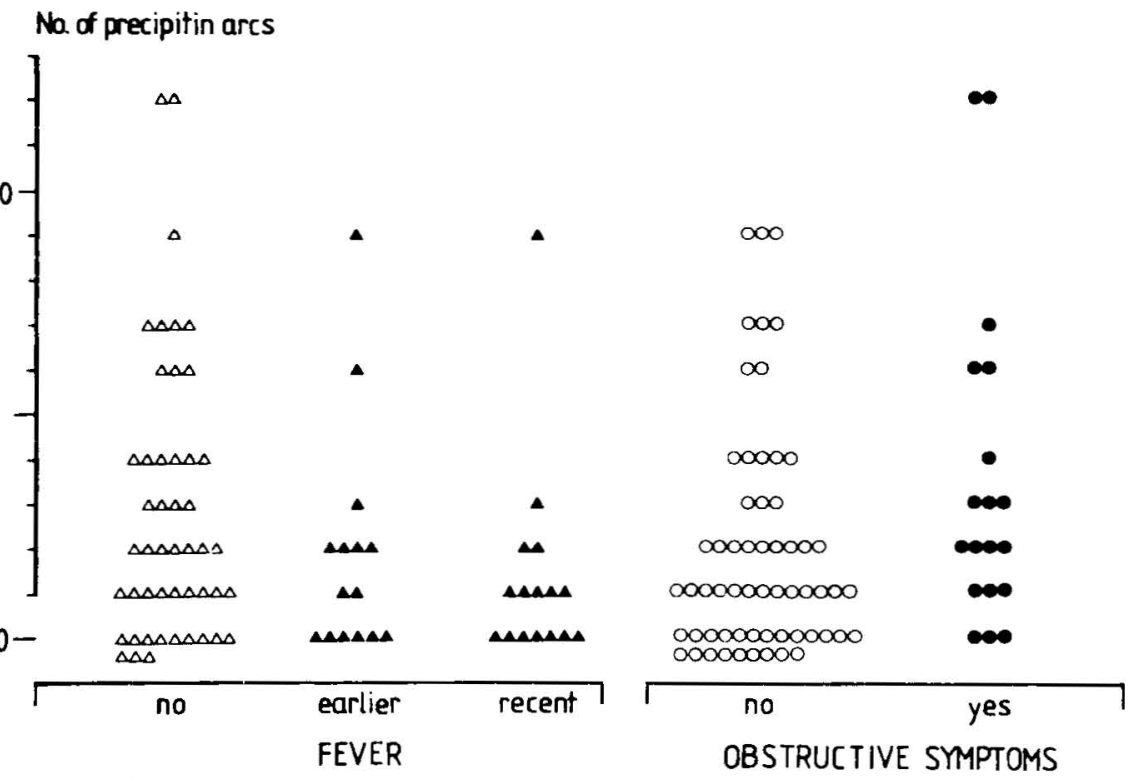

Figure 1. Total number of precipitin arcs against 16 different antigens measured with the immunoelectro-osmophoretic method using sera from farmers without febrile reactions ("no"), sera from farmers whose last febrile reaction occurred more than 2.5 years ago ("earlier"), and sera from farmers whose last febrile reaction occurred less than 2.5 years ago ("recent"). The right side of the figure represents the same farmers, but grouped according to the presence or absence of obstructive symptoms.

Table 3. Lung function and gas exchange in 45 farmers. ${ }^{2}$

\begin{tabular}{|c|c|c|c|c|c|c|c|c|}
\hline & \multicolumn{2}{|l|}{$\begin{array}{c}\text { Febrile } \\
\text { reaction } \\
\text { only } \\
(N=22)\end{array}$} & \multicolumn{2}{|c|}{$\begin{array}{l}\text { Obstruction } \\
\text { reaction } \\
\text { only } \\
(\mathrm{N}=7)\end{array}$} & \multicolumn{2}{|c|}{$\begin{array}{l}\text { Febrile }+ \\
\text { obstruction } \\
\text { reactions } \\
(N=4)\end{array}$} & \multicolumn{2}{|c|}{$\begin{array}{c}\text { No } \\
\text { reactions } \\
(N=17)\end{array}$} \\
\hline & $\begin{array}{l}\text { Percentage } \\
\text { of predicted }\end{array}$ & SD & $\begin{array}{l}\text { Percentage } \\
\text { of predicted }\end{array}$ & SD & $\begin{array}{l}\text { Percentage } \\
\text { of predicted }\end{array}$ & SD & $\begin{array}{l}\text { Percentage } \\
\text { of predicted }\end{array}$ & SD \\
\hline 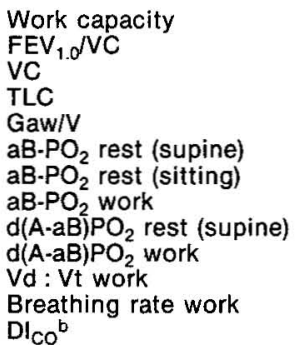 & $\begin{array}{r}108 \\
97 \\
105 \\
105 \\
97 \\
103 \\
96 \\
102 \\
92 \\
77 \\
119 \\
104 \\
97\end{array}$ & $\begin{array}{r}19 \\
7 \\
12 \\
10 \\
36 \\
13 \\
13 \\
8 \\
58 \\
29 \\
44 \\
33 \\
17\end{array}$ & $\begin{array}{c}107 \\
83^{\star} \\
103 \\
105 \\
79 \\
99 \\
90 \\
99 \\
92 \\
93 \\
111 \\
104 \\
91\end{array}$ & $\begin{array}{l}12 \\
18 \\
18 \\
16 \\
35 \\
16 \\
11 \\
11 \\
54 \\
50 \\
35 \\
22 \\
14\end{array}$ & $\begin{array}{r}101 \\
91 \\
102 \\
109 \\
80 \\
96 \\
96 \\
97 \\
109 \\
99 \\
131 \\
98 \\
96\end{array}$ & $\begin{array}{r}13 \\
5 \\
3 \\
6 \\
16 \\
7 \\
7 \\
5^{*} \\
44 \\
21^{*} \\
7 \\
8 \\
6\end{array}$ & $\begin{array}{r}109 \\
98 \\
107 \\
105 \\
93 \\
102 \\
97 \\
106 \\
87 \\
58 \\
98 \\
97 \\
100\end{array}$ & $\begin{array}{r}13 \\
7 \\
7 \\
10 \\
45 \\
8 \\
9 \\
7 \\
7 \\
59 \\
26 \\
46 \\
13 \\
18\end{array}$ \\
\hline
\end{tabular}

a Work capacity $=$ maximal exercise capacity, $F E V_{10} I V C=$ forced expiratory volume in $1 \mathrm{~s}$ as the percentage of vital capacity, $\mathrm{VC}=$ vital capacity, TLC $=$ total lung capacity, Gaw $/ V=$ volumic airways conductance, $a B-\mathrm{PO}_{2}=$ arterial blood oxygen tension, $\mathrm{d}(\mathrm{A}-\mathrm{a}) \mathrm{PO}_{2}=$ alveoloarterial difference in oxygen tension, $\mathrm{Vd}: \mathrm{Vt}=$ physiological dead space divided by tidal volume at submaximal work level $\left(150 \mathrm{~W}\right.$ men, $120 \mathrm{~W}$ women), $\mathrm{DL} \mathrm{CO}_{\mathrm{O}}=$ diffusion capacity according to the steady state method of Filley, measured at the same load as $\mathrm{Vd}: \mathrm{Vt}$.

b $\mathrm{DL}_{\mathrm{CO}}$ is the percentage of the mean value of the "no reaction" group.

" $p<0.005$, difference from the "no reaction" group.

There was a weak but negative correlation between the sum of the IEOP precipitates and the febrile history $(\mathrm{p}<0.05$ ) (figure 1 ).

There was a poor correlation between the $\operatorname{ID}(\mathrm{a})$ and ID(b) tests - similar immunodiffusion tests but with different antigen preparations. Only two sera displayed positive precipitin reactions to the same antigen in both tests. In 23 sera the reaction to the six comparable antigens was either positive in ID(a) and negative in ID(b) or vice versa.
Twenty subjects in the group with febrile reactions, eight in the group with unspecified symptoms, twelve referents, and five in the group with obstructive symptoms underwent complete physiological examinations. No statistically significant differences were found between those who had and those who had not had a febrile reaction to mold dust with regard to exercise capacity, lung function, or gas exchange (table 3 ). Subjects with a history of obstructive symptoms had a significantly lower forced 
expiratory volume in $1 \mathrm{~s}$ as the percentage of vital capacity $\left(\mathrm{FEV}_{1.0} / \mathrm{VC}\right)$. All 45 subjects had normal chest radiographs.

Twenty-four air samples from 21 farms were obtained during vigorous work with hay or grain. On 16 farms the farmer had complained of reactions to different materials (though not necessarily to the material tested), and five farms where no such reactions had occurred served as reference farms. One farmer had reported recurrent febrile reactions to moldy grain. Air collected from the respiration zone during the handling of this grain contained $2 \times 10^{9}$ microorganisms $/ \mathrm{m}^{3}$. The total number of microorganisms/1 of air divided into smaller and larger microorganisms $(<1.5 \mu \mathrm{m}$, probably bacteria, and $1.5-$ $5 \mu \mathrm{m}$, probably mold spores) is shown in figure 2 . The most common bacterial species were Streptomyces, Coryneform bacteria and Micrococcus. Typical molds were Aspergillus fumigatus and Penicillium in bad material and Alternaria, Cladosporium, and Fusarium in normal hay and grain.

\section{Discussion}

The results of the present study differ from those of several other investigations $(11,15,17,19,27)$. Moldy grain was the principal offender rather than moldy hay, and in addition moldy woodchips caused several febrile reactions. Only a few farmers showed positive precipitin reactions with the conventional immunodiffusion method.

Climatic factors and farming methods may explain why grain (and not hay) was the most common cause of mold exposure and febrile reactions. The climatic limit for growing barley is not far from the region investigated. The grain is harvested in SeptemberOctober, often with a high water content. It is dried by blowing outdoor air through the grain, sometimes at temperatures close to freezing. The majority of the febrile reactions occurred after the handling of grain which had become extremely moldy as a result of failure of the "cold air drying" method of storage. In contrast, the hay is prepared in June, in good weather, and is normally dried with air blown through the loosely stacked material in the barn until its water content reaches a safe, low level.

The low prevalence of precipitating antibodies against $M$ faeni antigens was probably not due to the antigen preparations used, since a high frequency of positive reactions has been observed in sera from Icelandic farmers with use of the same method [Id(a)] and antigen extracts (2). When the more sensitive IEOP test was employed, a higher frequency of positive sera was observed, but there was no (positive) correlation with febrile symptoms.

One possible explanation for the difference in the precipitin findings of our study and those of other studies might be that the Actinomycetes cultured in our samples were dominated by Streptomyces species

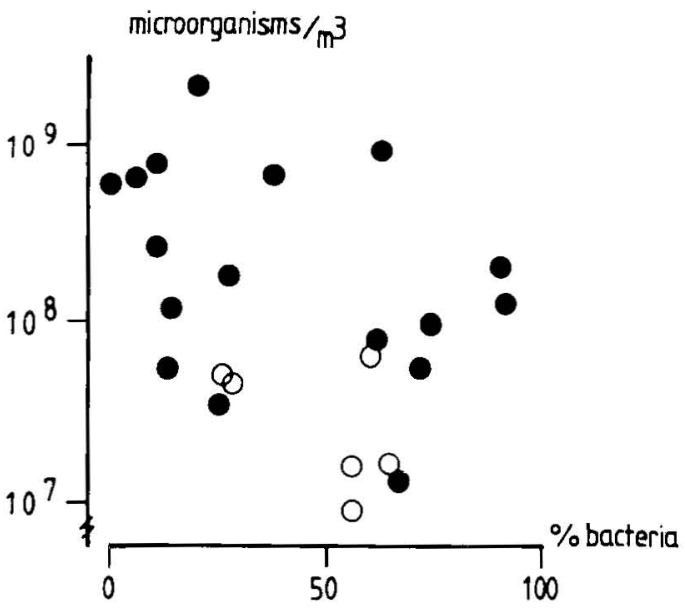

Figure 2. Number of microorganisms $/ \mathrm{m}^{3}$ in air samples obtained during work with hay and grain. Note the logarithmic scale of the $y$ axis. The $x$ axis represents the number of microorganisms of less than $1.5 \mu \mathrm{m}$ in diameter (probably bacteria) as a percentage of the total number. (Open circles: samples from farms without reports of reactions to organic dust; closed circles: samples from farms from which symptoms had been reported, though not necessarily from the material tested)

rather than $M$ faeni and Thermoactinomyces vulgaris, as reported from several other environments $(12,21)$.

One farmer with a negative precipitin test was exposed to $2 \times 10^{9}$ microorganisms $/ \mathrm{m}^{3}$ during work with moldy grain, which had caused repeated febrile reactions. Such exposure must constitute a considerable challenge to the defense mechanisms of the lung. According to medical records, another farmer, who had suffered a severe febrile reaction to moldy grain, had displayed inflammatory changes in the lungs, which regressed only after steroid treatment. However, the majority of the farmers had not sought medical advice for their symptoms, and thus it could not be determined whether or not the febrile reactions had been associated with inflammatory changes in the lungs. The chest radiographs and the extensive physiological investigations showed normal pulmonary function in farmers who had previously had febrile reactions.

Symptoms noted in a retrospective study constitute an uncertain basis for clinical diagnosis. But acute febrile reactions in farmers without precipitating antibodies are not typical of advanced cases of "classical farmer's lung" of the chronic type. This disease is associated with chronic granulomatous changes in the lung and high titers of precipitating antibodies against molds and bacteria.

It has been demonstrated, however, that acute massive exposure to mold dust may cause inflammatory changes in the lungs of patients without precipitating antibodies (8). Originally it was suggested that the reaction might be caused by mycotoxins, but this view has been challenged (7). 
It is not known to what extent precipitating antibodies are causally related to the inflammatory changes of allergic alveolitis (4). Possibly the low prevalence of antibodies in our material reflects the rather infrequent exposure to moldy grain noted in this study, in contrast to the daily exposure to mold dust resulting from work with moldy hay.

There was no association between febrile reactions and atopy. Some of these reactions appeared not to be associated with mold dust exposure and might have been caused by endotoxins from Gram-negative bacteria (24). Grain handler's disease is characterized by obstructive symptoms and febrile reactions to dust encountered in grain elevators and similar environments $(5,6)$. Some of the obstructive symptoms which occurred in $10 \%$ of the farmers in the present study may have been of a similar nature. Storage mites in hay (14), as well as pollen and animal dander, may also have contributed. The obstructive symptoms were not related to the febrile episodes, but were positively correlated with the serum $\operatorname{IgE}$ values. Farmers with obstructive symptoms had, on the average, a slightly decreased lung function.

The prevalence of symptoms was not of primary interest and indicated only an order of magnitude, since the material was biased. Still, it is clear that febrile reactions to mold dust and airway-obstructive reactions to other organic dusts constitute underdiagnosed health hazards in farm work. The high incidence of febrile reactions following exposure to moldy grain may be typical of farm work in northern Sweden. Since the farmers frequently did not seek medical attention for this condition, however, it is possible that febrile reactions induced by mold dust are also more common in other parts of the world than is usually appreciated.

\section{Acknowledgments}

We gratefully acknowledge the invaluable cooperation of Ms G Rand, registered nurse, from the Department of Occupational Medicine in Uppsala, Ms M Hellberg, registered nurse, and Ms B Lundgren, secretary of the Farmers' Safety and Health medical station in Hedemora, for their help in connection with the interviews, and technicians Ms B-M Sundblad and Ms A Abrahamsson for their skillful technical assistance during the physiological investigations. We would also like to thank $\mathrm{L}$ Belin, MD, at the Allergy Unit of the Department of Internal Medicine of Sahlgrenska Hospital in Göteborg, K Holmberg, MD, National Bacteriological Laboratory, Section of Medical Mycology, Stockholm, and G Johansson, MD, Department of Clinical Immunology, Karolinska Hospital, Stockholm, for performing the serological analyses of the blood samples.

This study was supported by grants from the Swedish Work Environment Fund, project 80-304, and the Swedish National Association Against Heart and Lung Diseases.

\section{References}

1. Belin L. Clinical and immunological data on "wood trimmer's disease"' in Sweden. Eur J Respir Dis Suppl 107 (1980) 169-175.

2. Belin L. The serological diagnosis in allergic alveolitis. In: Molina $C$, ed. Proceedings of the annual meeting of the European Academy of Allergology and Clinical Immunology. Technique et Documentation, Paris 1981, pp 121-128.

3. Berglund E, Birath G, Bjure J, Grimby G, Kjellmer I, Sandqvist L, Söderholm B. Spirometric studies in normal subjects: I Forced expirograms in subjects between 7 and 70 years of age. Acta Med Scand 173 (1963) $185-192$.

4. Burrell R, Rylander R. A critical review of the role of precipitins in hypersensitivity pneumonitis. Eur $\mathbf{J}$ Respir Dis 62 (1981) 332-343.

5. Cotton DJ, Graham BL, Li KYR, Froh F, Barnett GD, Dosman JA. Effects of grain dust exposure and smoking on respiratory symptoms and lung function. J Occup Med 25 (1983) 131-141.

6. DoPico GA, Flaherty D, Bhansali P, Chavaje N. Grain fever syndrome induced by inhalation of airborne grain dust. J Allergy Clin Immunol 69 (1982) 435-443.

7. Edwards JH, Wagner JC, Seal ME. Pulmonary responses to particulate materials capable of activating the alternative pathway of complement. Clin Allergy 6 (1976) 155-164.

8. Emanuel DA, Wenzel FJ, Lawton BR. Pulmonary mycotoxicosis. Chest 67 (1975) 293-297.

9. Filley GF, Gregoire F, Wright GW. Alveolar and arterial oxygen tensions and the significance of the alveolar-arterial oxygen tension difference in normal man. J Clin Invest 33 (1954) 517-529.

10. Fridriksson HV, Malmberg $\mathrm{P}$, Hedenström $\mathrm{H}$, Hillerdal G. Reference values for respiratory function tests in males: Prediction formulas with tobacco smoking parameters. Clin Physiol 1 (1981) 349-364.

11. Grant IWB, Blyth W, Wardrop VE, Gordon RM, Pearson JCG, Mair A. Prevalence of farmer's lung in Scotland: A pilot survey. Br Med J 1 (1972) 530-534.

12. Gregory PH, Lacey ME. Mycological examination of dust from moldy hay associated with farmer's lung. J Gen Microbiol 30 (1963) 75-88.

13. Hapke EJ, Seal RME, Thomas GO, Hayes M, Meek JC. Farmer's lung: A clinical, radiographic, functional, and serological correlation of acute and chronic stages. Thorax 23 (1968) $451-468$.

14. Ingram CG, Jeffrey IG, Symington IS, Cuthbert OD. Bronchial provocation studies in farmers allergic to storage mites. Lancet 2 (1979) 1330-1332.

15. Katila M-L. Respiratory disease in a farming population: A sero-epidemiological survey of farmer's lung and chronic nonspecific lung disease among dairy farmers in eastern Finland. Department of Clinical Microbiology, Kuopio, Finland 1978. (Doctoral dissertation).

16. Lacey J, Lacey ME. Spore concentrations in the air of farm buildings. Trans Br Mycol Soc 47 (1964) 547552.

17. Madsen D, Klock LE, Wenzel FJ, LaMar Robbins J, DuWayne Schmidt C. The prevalence of farmer's lung in an agricultural population. Am Rev Respir Dis 113 (1976) $171-174$.

18. Malmberg P, Fridriksson HV, Hedenström $\mathbf{H}$. Effects of age and tobacco smoking on gas exchange at rest and during exercise in healthy males. In: Fridriksson 
HV. Early changes in respiratory function caused by occupational dust or tobacco smoking. Uppsala University, Uppsala 1981, pp V: 1-18. (Doctoral dissertation).

19. Morgan DC, Smyth JT, Lister RW, Pethybridge RJ, Gilson JC, Callaghan P, Thomas GO. Chest symptoms in farming communities with special reference to farmer's lung. Br J Ind Med 32 (1975) 228-234.

20. Nordesjö LO, Landelius J. Clinical evaluation of physical work capacity. Scand J Clin Lab Invest 35 (1975): suppl 143, 64.

21. Pepys J. Hypersensitivity diseases of the lungs due to fungi and other organic dusts. S Karger, Basel 1969. (Monographs in allergy 4).

22. Pepys J, Jenkins PA. Precipitin (FLH) test in farmer's lung. Thorax 20 (1965) $21-35$.

23. Ramström L, Nordgren P. Tobaksvanor i Sverige 1981. Tobaken och Vi 27 (1982) 23-27.

24. Rylander R, Snella M-C. Endotoxins and the lung:
Cellular reactions and risk for disease. Prog Allergy 33 (1982) $332-344$.

25. Terho EO. Microbiological and serological studies on farmer's lung disease. University of Kuopio, Kuopio 1978. (Publications of the University of Kuopio, Medicine. Series Original Reports 1).

26. Wadström T. Immunoelectro-osmophoresis or counterimmunoelectrophoresis. Scand J Immunol 17 (1983): suppl 10, 97-102.

27. Warren CPW. Lung disease in farmers. Can Med Assoc J 116 (1977) 391-394.

28. Zimmermann R, Meyer-Reil L-A. A new method for fluorescence staining of bacterial populations on membrane filters. Kiel Meeresforsch 30 (1974) 24-27.

Received for publication: 3 October 1985 